\title{
Influência da rota alcoólica e razão tensoativo/argila no processo de organofilização de argilas bentoníticas e em suas propriedades reológicas em meios não aquosos
}

\author{
(Influence of alcohol route and surfactant/clay ratio in the \\ process of bentonite clays organophilization and their rheological \\ properties in non-aqueous media)
}

\author{
S. L. A. Dantas, K. A. Marques, H. S. Ferreira \\ UFPB/CT/DEMat, Cidade Universitária s/n, João Pessoa, PB \\ suylanlourdes@hotmail.com,kaiomarques93@hotmail.com,hebersivini@gmail.com
}

\begin{abstract}
Resumo
Argilas bentoníticas podem ser definidas como sendo uma argila constituída essencialmente de argilominerais do grupo das esmectitas, especialmente a montmorilonita. Não sendo as argilas bentoníticas naturalmente organofílicas, estas podem ser modificadas através de tratamentos específicos com tensoativos (iônicos ou não-iônicos), passando sua natureza de hidrofílica para hidrofóbica. As argilas organofilicas são amplamente utilizadas como agentes viscosificantes na mistura de componentes usados para a perfuração de poços de petróleo e água entre outros usos. Estudos recentes demonstraram a influência do tipo de argila, tensoativo e presença de defloculante na reologia das dispersões. Neste trabalho verificamos a influência da rota alcoólica, do teor de argila e tensoativo na produção de argilas organofilicas e no comportamento reológico final em meios não aquosos. Para tanto, realizamos a caracterização das amostras de argilas através de análise termogravimétrica, difração de raios X, análise térmica diferencial e análise granulométrica. As argilas organofílicas foram caracterizadas por difração de raios X e fluorescência de raios X. Por fim foram produzidas dispersões de acordo com normatização da Petrobras para realização dos ensaios reológicos. Os resultados evidenciaram que existe influência da razão argila/tensoativo e da rota alcoólica nas propriedades reológicas das dispersões.
\end{abstract}

Palavras-chave: reologia, teor de tensoativo, teor de argila, rota alcoólica.

\section{Abstract}

Bentonite clays can be defined as clays consisting predominantly of the smectite group clay minerals, particularly montmorillonite. Naturally, the bentonite clays are not organophilic, these can be modified by treatment with specific surfactants (ionic or nonionic), turning from hydrophobic to hydrophilic. The organophilic clays are widely used as viscosifying agents in the mixture of components used for oil and water well drilling among other uses. Recent studies have demonstrated the influence of clay type, the presence of surfactant and dispersant on rheology. In this study we verified the influence of alcoholic route, clay and surfactant content in the production of organophilic clays and in the final rheological behavior in non-aqueous media. Thus, we performed the characterization of samples of clays by thermogravimetric analysis, X-ray diffraction, differential thermal analysis and particle size analysis. The organoclays were characterized by X-ray diffraction and X-ray fluorescence. Finally, dispersions were produced according to standards by Petrobras to perform normalization rheological tests. The results indicated that there is the influence of clay/surfactant ratio and the alcoholic route on the rheological properties of dispersions

Keywords: rheology, surfactant content, clay content, alcoholic route.

\section{INTRODUÇÃO}

A argila é uma das substâncias naturais mais importantes em utilização nas indústrias, tendo uma variedade de produtos que se fazem com ela e com a ajuda dela. Possuindo vasto campo de aplicações, desde o barro bruto impuro até as mais finas qualidades fornecidas pelas usinas de beneficiamento, com pureza garantida por análises químicas, exames físicos e controle eletrônico. Dessa forma, as argilas utilizadas nas indústrias são de grande valor econômico [1]. As bentonitas, apesar da conceituação geológica clássica, modernamente podem ser consideradas como qualquer argila constituída por argilominerais do grupo da esmectita que apresentem propriedades similares as bentonitas clássicas [2]. A modificação das bentonitas pode ser feita por vários mecanismos. Os mais estudados são troca catiônica, onde tensoativos iônicos, principalmente os sais quaternários de amônio, são adicionados em dispersões aquosas de bentonitas altamente delaminadas de forma a permitir a substituição dos cátions trocáveis da argila pelo tensoativo, e adsorção, onde os tensoativos não iônicos são adsorvidos, também em meios aquosos, por interações íon-dipolo [3]. 
Os álcoois, como também etileno glicol e glicerina, são utilizados na identificação das argilas esmectíticas, tendo em vista que ao se intercalar entre as camadas 2:1 do argilomineral, provocam o aumento da distância basal, passando de valores entre $14-15 \AA$ para valores $\sim 17 \AA$ [4]. Este fato, observado do ponto de vista do processo de organofilização, favorecerá a intercalação do tensoativo entre as lamelas de argila. Não há estudos que utilizem a rota alcoólica como etapa preliminar ao tradicional processo de intercalação de tensoativos. Sob este aspecto, trata-se de um processo inovador e promissor. O uso do álcool etílico em suspensões cerâmicas tem o intuito de mudar o caráter da suspensão de Newtoniano para não-Newtoniano. De inicio, a adição do álcool expande o espaço interlamelar da argila para posterior aumento da viscosidade do meio. Com o propósito de aumentar a viscosidade de uma suspensão cerâmica, acrescenta-se álcool etílico à suspensão, identificase que o aumento da quantidade de álcool é proporcional a variação de viscosidades alcançadas [5].

A argila bentonitica, quando associada a um álcool aromático, vai promover uma reação de substituição eletrofílica aromática, podendo tomar vários caminhos, dependendo da quantidade de anéis aromáticos na molécula. Este comportamento se dá devido ao efeito indutivo causado pelo anel aromático e a diferença significativa de energia entre os intermediários da reação, favorecendo a formação de compostos assimétricos [6].

Atualmente, as argilas organofílicas são amplamente estudadas na forma de agentes tixotrópicos em perfurações de poços de petróleo [7, 8]. Há também estudos de caracterização dos componentes empregados na preparação das dispersões argilosas precursoras do processo de organofilização, como também estudos que relacionam o tipo de tensoativo utilizado e a reologias das dispersões, de forma que este trabalho completará uma lacuna existente otimizando o processo $[3,9,10]$. Desta forma, o objetivo principal deste trabalho é estudar a influência da adição de álcool etílico no processo de dispersão de argilas bentoniticas, sua consequente influência no processo posterior de organofilização. Durante o processo de organofilização ainda serão estudadas a relação da razão argila/tensoativo e o tipo de tensoativo. Por fim, o comportamento reológico das dispersões preparadas a partir das argilas organofilicas obtidas nas condições acima será determinado e comparado à normatização existente.

\section{MATERIAIS E MÉTODOS}

A argila bentonítica utilizada foi a argila Bentongel, cujo fabricante é a Bentonisa, proveniente do município de Boa Vista, PB. Como agente dispersante utilizou-se o óleo diesel comercial, da distribuidora BR. No processo de organofilização utilizou-se o álcool etílico absoluto F. Maia Ind. Com. Ltda, para o ajuste do $\mathrm{pH}$ das amostras ácido clorídrico, densidade $1,19 \mathrm{~g} / \mathrm{mL}$ e $37 \%(\mathrm{~m} / \mathrm{m})$, Vetec. Para solução salina saturada foi utilizado cloreto de sódio P.A., reagente analítico P.M. 58,44 CAS: 7647-14-5, F. Maia. O tensoativo de caráter iônico foi o Praepagem WB, Clariant S.A., S. Paulo, SP, e o tensoativo de caráter não iônico foi a amina etoxilada de grau 5, TA50, Oxiteno, Mauá, SP.

As argilas bentoniticas industriais foram caracterizadas antes e depois da organofilização com os tensoativos iônicos e não-iônicos. A caracterização das amostras de argilas bentoníticas foi efetuada por meio dos seguintes métodos: capacidade de troca de cátions pelo método de adsorção do azul de metileno (CTC) [11], análise granulométrica por difração de laser (AG), difração de raios X (DRX), análise termogravimétrica (TG) e análise térmica diferencial (ATD). As dispersões argila+água+álcool foram caracterizadas reologicamente por meio da medida das viscosidades aparente e plástica. Após a organofilização as amostras foram caracterizadas por difração de raios $\mathrm{X}$ e fluorescência de raios X (FRX). A viscosidade aparente das emulsões preparadas com as argilas organofilizadas e a fase dispersiva (óleo diesel) foi determinada em um viscosímetro Fann 35A.

\section{Preparação das dispersões (água + argila + álcool)}

Na preparação das dispersões foram utilizadas as argilas nas seguintes concentrações: $3,16 \%, 4,16 \%, 5,16 \%, 6,16 \%$ e $7,16 \%$, em massa de argila. No preparo da dispersão, a massa pesada da argila é misturada com água destilada+álcool etílico na temperatura ambiente com agitação de $1500 \mathrm{rpm}$ por $20 \mathrm{~min}$, as proporções da razão água/álcool estudadas foram $25 \% / 75 \%, 50 \% / 50 \%$ e $75 \% / 25 \%$. Após esse tempo de agitação a dispersão é deixada em repouso por $24 \mathrm{~h}$.

\section{Processo de organofilização - tensoativo iônico Praepa- gem $W B$}

O processo de organofilização consiste na adição do tensoativo iônico Praepagem WB na dispersão pronta com teores de 1,07 CTC, 1,29 CTC, 1,50 CTC, 1,72 CTC e 1,94 CTC (1 CTC = CTC da argila em estudo) denominadas respectivamente amostras 1 a 5, seguida de agitação contínua por 20 min para posterior filtração a vácuo e lavagem. A secagem foi de $24 \mathrm{~h}$ a $66^{\circ} \mathrm{C}$.

Processo de organofilização - tensoativo não iônico TA 50

O processo de organofilização com tensoativo nãoiônico TA-50 é feito de maneira similar ao anterior, porem com teores em massa de 13,74 g, 15,80 g, 17,86 g, 19,24 g e $21,29 \mathrm{~g}$, denominadas amostras 1 a 5 , pois não é possível a correlação com a CTC, uma vez que o tensoativo não possui carga. Estes teores são os mesmos, em massa, adicionados para a organofilização com o tensoativo iônico. O TA 50 tem por característica deixar a mistura com caráter básico, sendo necessário o reajuste de seu $\mathrm{pH}$ para 7,0, por meio da adição de ácido clorídrico $1 \mathrm{M}[12,13]$, com intuito de tornála neutra e permitir a completa interação do tensoativo com as partículas de argila. A filtração, lavagem e secagem foram feitas da mesma maneira citada anteriormente. 
Preparação das dispersões não aquosas

$\mathrm{Na}$ preparação das dispersões não aquosas utilizase $275 \mathrm{~g}$ da base (óleo diesel) com $84 \mathrm{~mL}$ da solução de cloreto de sódio saturada sob agitação por $5 \mathrm{~min}$. Esta emulsão é denominada lama base. A argila organofilica foi adicionada à lama base com uma variação da massa de 2,4 g, 6,0 g, 9,6 g, 13,2 g (N- EP-1EP-00023-A [14]) em agitação por 20 min. Após a preparação, a dispersão foi levada para estufa a $66{ }^{\circ} \mathrm{C}$ por $16 \mathrm{~h}$ para que ocorresse seu envelhecimento. Após esse tempo de envelhecimento, foi medida a viscosidade aparente. Foram utilizadas na nomenclatura dos gráficos as seguintes siglas: massa 1 corresponde a 2,4 g de argila; massa 2, 6,0 g; massa 3, 9,6g; e massa 4, 13,2g. Esses valores são estabelecidos pela norma EP-1EP-00023-A [14] da Petrobras.

\section{RESULTADOS E DISCUSSÃO}

A argila apresentou CTC de 83,499 meq/100 g de argila, (este valor é considerado $1 \mathrm{CTC}$ neste trabalho) valor típico de argilas bentoniticas sódicas do município de Boa Vista, PB [15].

A Fig. 1 apresenta o resultado da análise granulométrica da argila. Observa-se um comportamento monomodal com diâmetro médio equivalente das partículas $\mathrm{D}_{\mathrm{M}}=5,84 \mu \mathrm{m}$. Em relação ao volume acumulado, apresenta $21 \%$ de partículas com diâmetro médio equivalente abaixo de $2 \mu \mathrm{m}$, que corresponde à fração argila, e maior concentração de partículas entre $4 \mathrm{e}$ $8 \mu \mathrm{m}$. As demais frações acima de $2 \mu \mathrm{m}$ são provavelmente aglomerados e agregados de argila não dispersos durante o processo de determinação da granulometria [11].

A Fig. 2 mostra o difratograma de raios $\mathrm{X}$ da argila

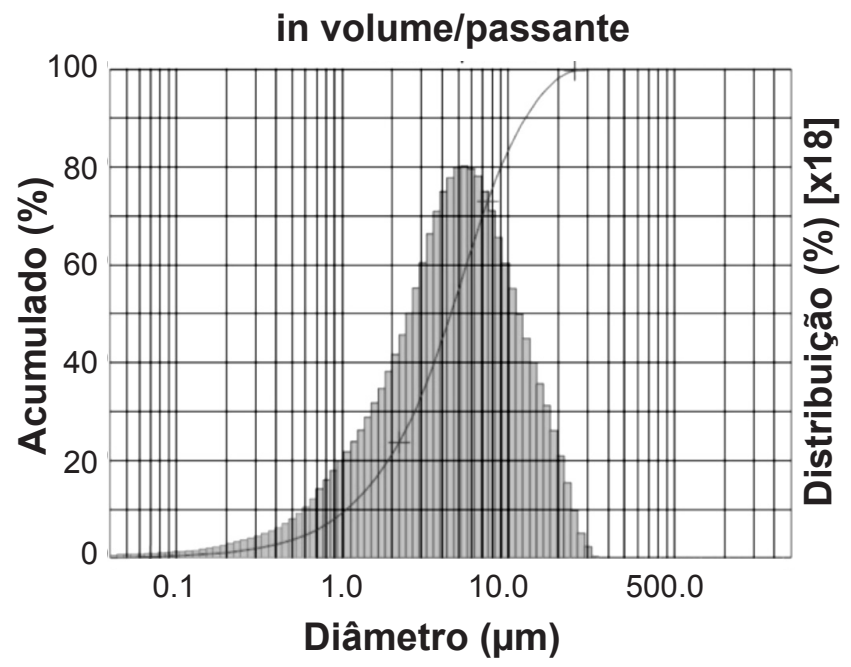

Figura 1: Distribuição do tamanho de partículas da argila Bentongel. [Figure 1: Particle size distribution of Bentongel clay.]

Bentongel. Além do argilomineral esmectítico, estão presentes caulinita e quartzo na forma de minerais contaminantes. $\mathrm{O}$ argilomineral esmectítico é caracterizado pelas distâncias interplanares basais de 14,07 $\AA$ e 4,45 $\AA$,

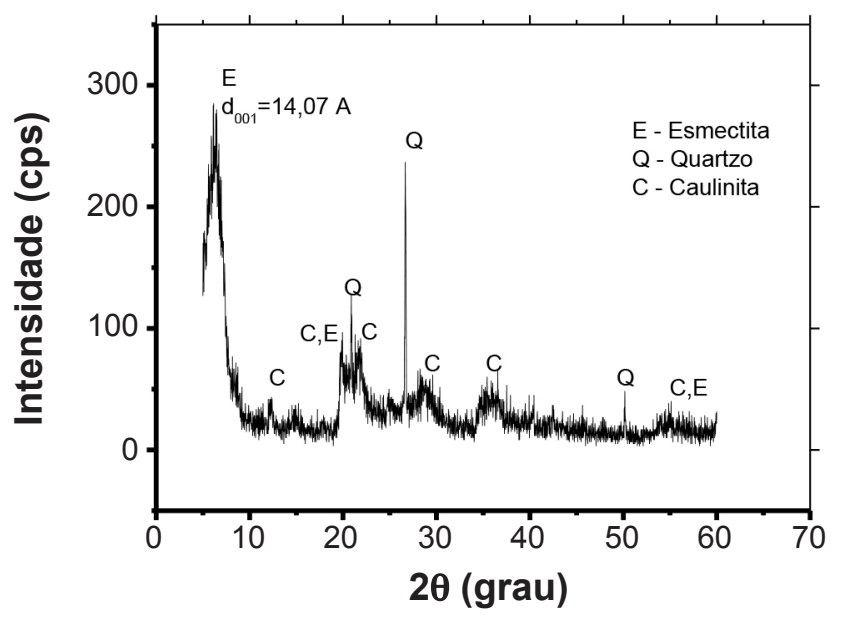

Figura 2: Difratograma de raios $\mathrm{X}$ da argila Bentongel. [Figure 2: X-ray diffraction pattern of Bentongel clay.]

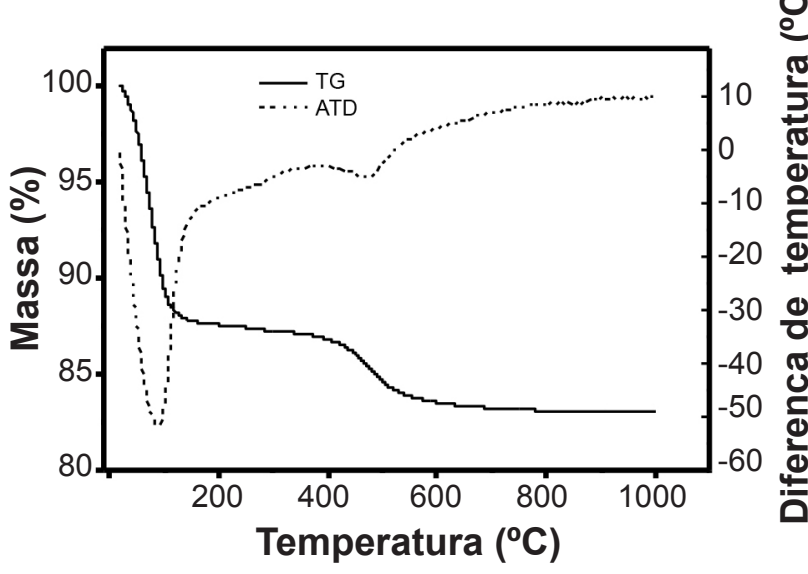

Figura 3: Curvas de análise térmica da argila Bentongel. [Figure 3: Thermoanalysis curves of Bentongel clay.]

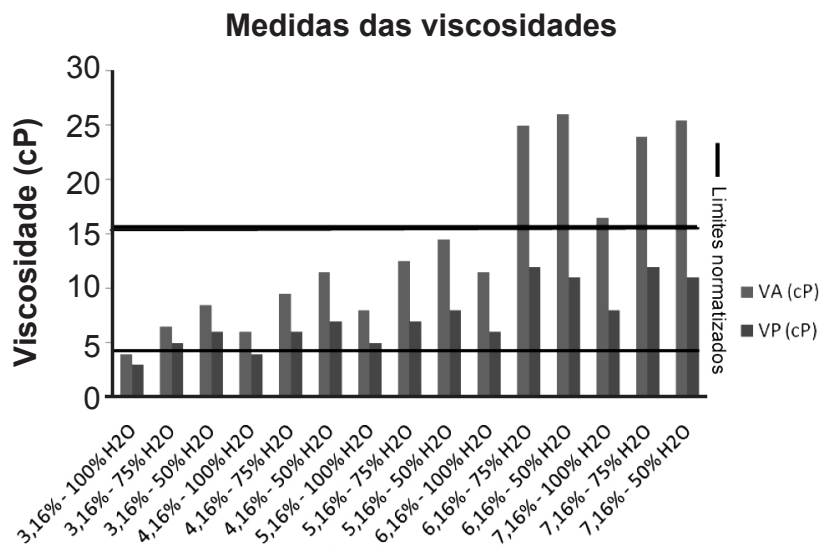

\section{Amostras}

Figura 4: Viscosidades aparente e plástica das dispersões de argila+água+álcool. Normatização Petrobras N-EP-1EP-00011-A [17]: $\mathrm{VA} \geq 15 \mathrm{cP}$ e $\mathrm{VP} \geq 4 \mathrm{cP}$.

[Figure 4: Apparent and plastic viscosities of dispersions of clay + water + alcohol. Standard Petrobras N-EP-1EP-00011-A [17]: $V A \geq 15 c P$ and $V P \geq 4 c P$.] 
o quartzo tem como picos característicos 4,23 $\AA$ e $3,34 \AA$ e a caulinita é identificada pelos picos de $7,15 \AA, 4,45 \AA$ e $4,35 \AA$. De modo geral, o difratograma é típico das argilas bentoníticas de Boa Vista, PB [11].

Na Fig. 3 estão apresentadas as curvas de análise termogravimétrica e análise térmica diferencial da argila Bentongel.

Observamos na curva de TG dois eventos térmicos. O primeiro tem início em $\sim 25{ }^{\circ} \mathrm{C}$ e término em $\sim 133{ }^{\circ} \mathrm{C}$, correspondendo à perda de água absorvida da argila com perda de massa de $\sim 12,5 \%$. O segundo evento, variando entre $400{ }^{\circ} \mathrm{C}$ e $550{ }^{\circ} \mathrm{C}$, corresponde à perda de hidroxilas da argila bentonítica, sendo constatada uma perda de massa de $4,6 \%$. A perda total foi de $17,1 \%$. Não foi encontrado nenhum evento correspondente a carbono livre, portanto, tem-se ausência de matéria orgânica na amostra bentongel [15]. No gráfico de análise térmica diferencial, pode-se notar os seguintes eventos térmicos: pico endotérmico com
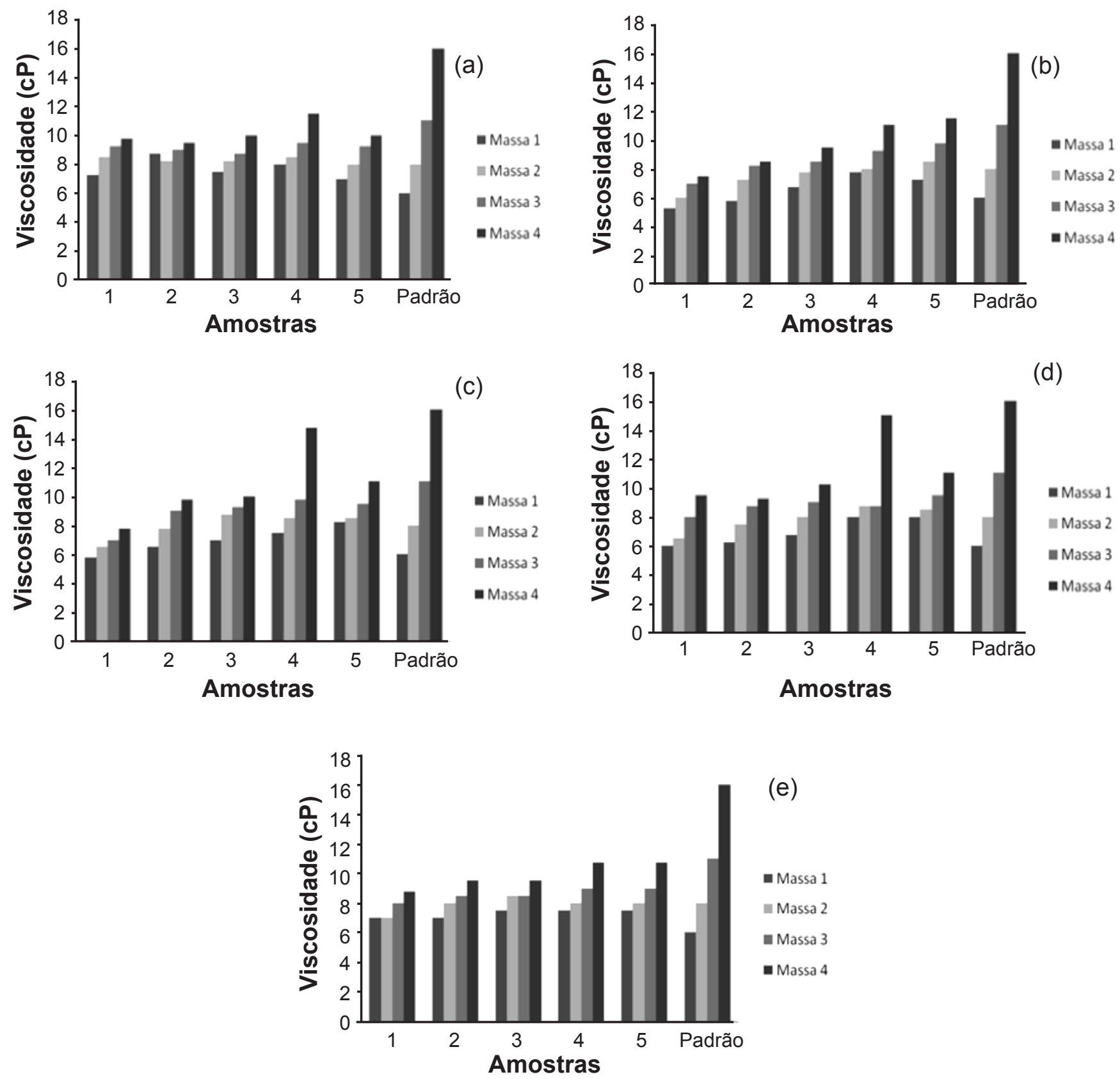

Figura 5 (a): Viscosidade aparente (VA) das dispersões de lama base com argilas organofilicas Bentogel 3,16\% TA50; (b): com argilas organofilicas Bentogel 4,16\% TA50; (c): com argilas organofilicas Bentogel 5,16\% TA50; (d): com argilas organofilicas Bentogel $6,16 \%$ TA50; (e): com argilas organofilicas Bentogel 7,16\% TA50.

[Figure 5 (a): Apparent viscosity (AV) dispersions of base mud with organophilic clays Bentongel 3.16\% TA50; (b): with organophilics clays Bentongel 4.16\% TA50; (c): with organophilics clays Bentongel 5.16\% TA50]; (d): with organophilics clays Bentongel 6.16\% TA50; (e): with organophilics clays Bentongel 7.16\% TA50.] 
máximo em $90{ }^{\circ} \mathrm{C}$ característico da presença de água livre e conseqüente evaporação, pico endotérmico com máximo em $470{ }^{\circ} \mathrm{C}$ correspondendo à liberação de hidroxilas. E pequeno pico endotérmico a $850{ }^{\circ} \mathrm{C}$ correspondente à destruição da rede cristalina [16].

AFig. 4 mostra o comportamento reológico das dispersões argila+água+álcool. Muitas das amostras não atingiram os valores mínimos estipulados pela normatização da Petrobrás

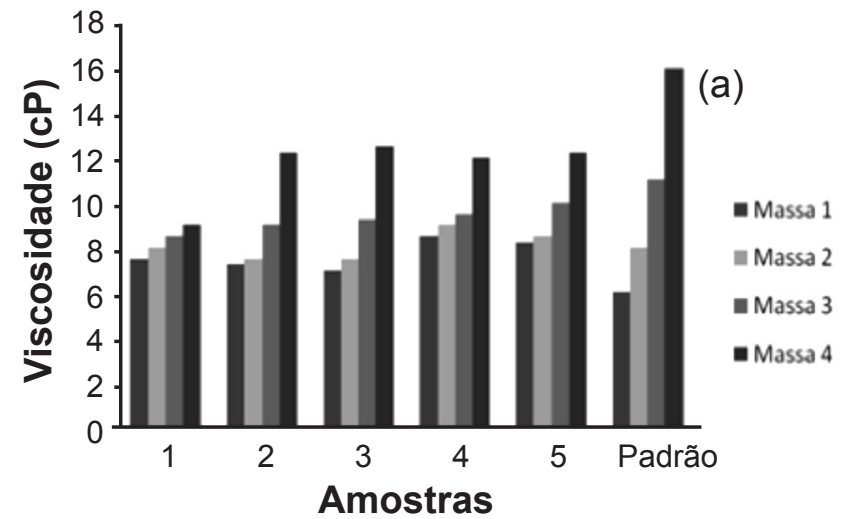

Figura 6 (a): Viscosidades aparente (VA) das dispersões de lama base com argilas organofilicas Bentogel 3,16\% WB.

[Figure 6 (a): Apparent viscosities (AV) dispersions of base mud with organophilics clays Bentongel 3.16\% WB.]

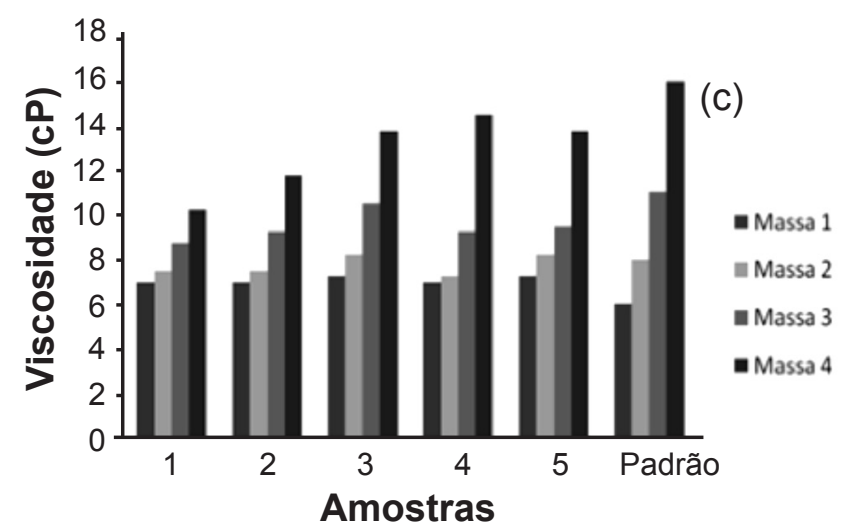

Figura 6 (c): Viscosidades aparente (VA) das dispersões de lama base com argilas organofilicas Bentogel 5,16\% WB.

[Figure 6 (c): Apparent viscosities (AV) dispersions of base mud with organophilics clays Bentongel 5.16\% WB.]

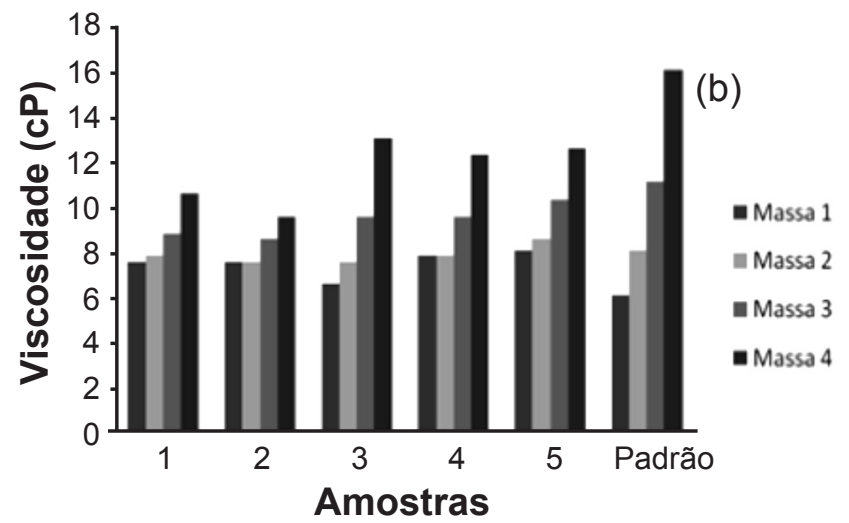

Figura 6 (b): Viscosidades aparente (VA) das dispersões de lama base com argilas organofilicas Bentogel 4,16\% WB.

[Figure 6 (b): Apparent viscosities (AV dispersions of base mud with organophilics clays Bentongel 4.16\% WB.]

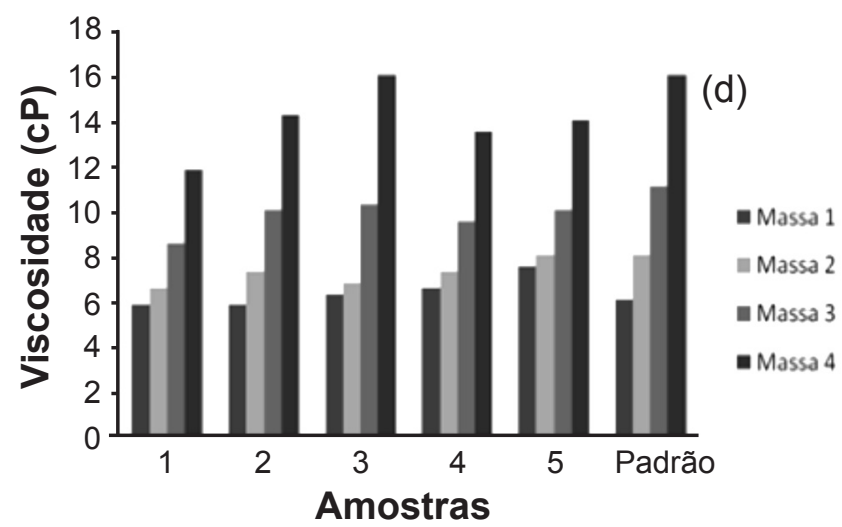

Figura 6 (d): Viscosidades aparente (VA) das dispersões de lama base com argilas organofilicas Bentogel $6,16 \% \mathrm{WB}$.

[Figure $6(d)$ : Apparent viscosities (AV) dispersions of base mud with organophilics clays Bentongel 6.16\% WB.]

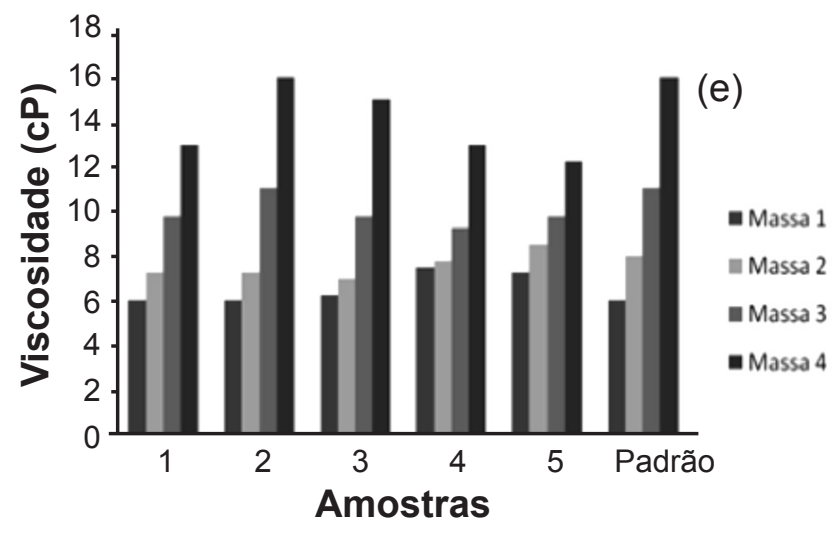

Figura 6 (e): Viscosidades aparente (VA) das dispersões de lama base com argilas organofilicas Bentogel 7,16\% WB.

[Figure 6 (e): Apparent viscosities (AV) dispersions of base mud with organophilics clays Bentongel 7.16\% WB.] 
(N-EP-1EP-00011-A [17]: $\mathrm{VA} \geq 15 \mathrm{cP}$ e $\mathrm{VP} \geq 4 \mathrm{cP}$ ), fazendo com que seja necessária a classificação dos resultados como mais próximos da norma.

As amostras de argila Bentongel com os teores de $50 \%$ de $\mathrm{H}_{2} \mathrm{O}$ e $50 \%$ de álcool apresentaram os melhores valores de viscosidades, isso pode ser explicado provavelmente devido à maior delaminação das camadas da argila com a presença do álcool neste teor, assim pode-se verificar que no processo de organofilização o tensoativo terá uma maior facilidade de se intercalar entre as camadas da argila sendo este o teor de álcool a ser utilizado no processo de organofilização a ser empregado neste trabalho [5].

O processo de organofilização visto por difração de raios $\mathrm{X}$ (não apresentado aqui na forma gráfica) indica a modificação do valor de $\mathrm{d}_{001}$ da argila de 14,07 $\AA$ para $\sim 41,4$ Å para o tensoativo WB e 44,5 $\AA$ para o tensoativo TA50 nos maiores teores de tensoativo. Foi observado um aumento gradual de intensidades à medida que os teores de tensoativo eram acrescidos, evidenciando a formação de uma estrutura mais organizada do ponto de vista cristalográfico [18]. Não existe modificação significativa quando da variação da concentração de argila.

Em uma análise de todos os resultados de difração de raios $\mathrm{X}$ das argilas organofilicas, tanto para as amostras preparadas com o tensoativo iônico como com o tensoativo não iônico, foi observado que o acréscimo do álcool etílico no teor de $50 \%$ no processo de organofilização foi de grande importância, pois os valores encontrados de $d_{001}$ como o progressivo aumento nas intensidades dos picos característicos, em comparação com os dados da literatura evidenciaram uma melhor intercalação do ponto de vista da difração [19].

Sem o uso do álcool no processo de organofilização, já se obtinha grandes espaçamentos entre as camadas da argila, com uma média de aproximadamente $37 \AA$ para ambos os tensoativos [12]. Com o acréscimo do álcool etílico na realização da organofilização com o tensoativo TA50, foi observado um aumento em torno de 7,56 $\AA$ ou $16 \%$ em relação às amostras de argila sem a presença do álcool [12]. $\mathrm{Na}$ organofilização com o tensoativo Praepagem WB, foi observado um acréscimo em torno de $3,41 \AA$ ou $10,5 \% \mathrm{em}$ relação às amostras de argila sem a presença do álcool [11].

O processo de organofilização, visto por fluorescência de raios X (não apresentado aqui em forma gráfica) indica a presença crescente de carbono, antes ausente, como visto nas análises térmicas, proveniente do tensoativo orgânico, à medida que seus teores são elevados.

As Figs. 5 a, b, c, d, e apresentam os gráficos das viscosidades aparentes das dispersões de lama base com argilas organofilicas tratadas com o tensoativo TA 50 comparadas com o padrão [14].

De maneira geral, no caso do tensoativo TA 50, as dispersões com os teores de massa 1 e 2 conduzem a resultados uniformes e sempre dentro das normas; já os teores de massa 3 e 4 sempre apresentam-se abaixo dos limites normatizados, não sendo de significativa importância o teor de argila nem o teor de tensoativo. Observa-se um comportamento semelhante à adição de uma carga inerte. Deste modo, pode-se dizer que o tensoativo não iônico TA50 teve um bom comportamento na organofilização da argila bentonítica, sendo comprovado na análise de difração de raios X, com valores altos de distância basal; entretanto, nos testes de viscosidades das dispersões fica demonstrado pouca afinidade com o meio dispersante, o que resulta em propriedades reológicas abaixo dos limites normatizados não sendo adequado para esta aplicação. Essa pouca afinidade deve ao fato do tensoativo possuir em suas extremidades um grupo polar, a hidroxila, e o óleo diesel ser essencialmente um alcano com cadeia contando com entre 6 e 30 átomos de carbono, e completamente apolar.

As Figs. 6 a, b, c, d, e apresentam os gráficos das viscosidades aparentes das dispersões de lama base com argilas organofilicas tratadas com o tensoativo WB comparadas com o padrão [14].

É notoria a proximidade entre os valores experimentais e os valores padronizados, houve um significativo acréscimo nas viscosidades aparentes experimentais em relação ao TA 50 , principalmente nas massas 3 e 4 para cada concentração de tensoativo, isso confirma uma melhor afinidade química entre a argila organofilizada com o tensoativo WB e a lama base de óleo diesel. Essa afinidade advem da natureza apolar do tensoativo, que possui em suas extremidades cadeias carbonicas acíclicas, saturadas e homogêneas, portanto apolares, que são misiveis em meios apolares com o oleo diesel, componente principal da lama base. Este tensoativo é adquado para esta aplicação.

Deste modo, pode-se dizer, neste caso, que o teor de tensoativo se mostrou uma variável importante nos estudos reológicos, já o teor de argila se mostrou uma variável pouco significativa. As amostras com os melhores resultados foram, $6,16 \%$ de argila para a composição 3 de tensoativo e a amostra de 7,16\% de argila e composição 2 de tensoativo, para o tensoativo Praepagem WB que satisfizeram a normatização existente.

Uma analise conjunta e todos os resultados indicam que a rota alcoólica utilizada neste trabalho promoveu um maior aumento dos espaçamentos interplanares durante o processo de organofilização $[11,12]$ e que este aumento permitiu a obtenção de argilas organofilicas com propriedades reológicas dentro dos limites normatizados. Fato ainda não reportado na literatura com argilas provenientes de Boa Vista, PB $[4,11,12]$.

\section{CONCLUSÕES}

O processo de dispersão e organofilização via rota alcoólica se mostrou eficiente, podendo ser comprovado com o aumento da distância interplanar basal nas amostras da argila para valores acima dos descritos na literatura, identificados pela análise de difração de raios $\mathrm{X}$, provavelmente devido à maior delaminação provocada pelo álcool durante o processo de dispersão. No estudo da viscosidade das dispersões, apenas as massas com 2,4 g e 6,0 $\mathrm{g}$ para todas as amostras de argila e tensoativo apresentaram 
valores de viscosidade aparente dentro dos estabelecidos pela norma EP-1EP-00023A [12], tanto para o tensoativo TA50 como para o Praepagem WB. Podem-se destacar as amostras: $6,16 \%$ de argila para a amostra 3 a e $7,16 \%$ de argila para a amostra 2 com tensoativo Praepagem WB para ambos os casos, que apresentaram comportamento reológico dentro dos limites normatizados. Portanto, pode-se concluir que a rota alcoólica é uma variável importante e promissora nos estudos reológicos, bem como a razão tensoativo/argila e tipo de tensoativo. Já o teor de argila se mostrou uma variável pouco significativa, devendo-se optar por dispersões mais concentradas como forma de otimizar o rendimento do processo de obtenção de agentes organofilicos.

\section{AGRADECIMENTOS}

Ao CNPq pelo auxílio financeiro.

\section{REFERÊNCIAS}

[1] H. S. Ferreira, A. B. Martins, D. L. Costa, E. Teixeira Neto, T. J. A. Melo, G. A. Neves, H. C. Ferreira, Anais $52^{\circ}$ Cong. Bras. Ceram., Florianópolis, SC (2008) 77-85.

[2] Y. Shen, Chemosphere 41 (2000) 711-716.

[3] L. B. Paiva, A. R. Morales, F. R. Valenzuela Diaz, Appl. Clay Sci. 42 (2008) 8-24.

[4] F. R. Valenzuela Diaz, "Preparação, a nível de laboratório, de algumas argilas esmectíticas organofílicas", Tese Dr., Escola Politécnica da Universidade de S. Paulo, SP (1994).

[5] E. Santoyo, S. Santoyo-Gutierrez, A. Garcia, G. Espinosa, S. L. Moya, Appl. Thermal Eng. 21 (2001) 283-302.

[6] R. Salcedo, M. Salmo, A. Cabrera, L. E. Sansores, J.
Molecular Structure (Theochem.) 497 (2000) 75-82.

[7] J. C. A. A. Roelofs, P. H. Berben, Appl. Clay Sci. 33 (2006) 13-20.

[8] O. A. Falode, O. A. Ehinola, P. C. Nebeife, Appl. Clay Sci. 39 (2008) 19-27.

[9] V. Mahto, V. P. Sharma, J. Petroleum Sci. Eng. 45 (2004) 123-128.

[10] L. V. Amorim, C. M. Gomes, F. L. H. Silva, H. C. Ferreira, Cerâmica 48 (2002) 308.

[11] H. S. Ferreira, L. F. A. Campos, R. R. Menezes, J. M. Cartaxo, L. N. L. Santana, G. A. Neves, H. C. Ferreira, Cerâmica 59 (2013) 277-284.

[12] F. K. A. Sousa, A. P. Ramos, L. F. A. Campos, R. R. Menezes, H. S. Ferreira, G. A. Neves, Cerâmica 57 (2011) 199-205.

[13] Y. Shen, Chemosphere 44 (2001) 989-995.

[14] Norma EP-1EP-00023-A, “Argila organofílica para fluidos de perfuração à base de óleo - especificação e método de ensaio", Petrobras (2011).

[15] P. Souza Santos, Ciência e Tecnologia de Argilas, Vol. 1, Editora Edgard Blücher, S. Paulo, SP (1989)190.

[16] P. Souza Santos, Ciência e Tecnologia de Argilas, Vol. 2, Editora Edgard Blücher, S. Paulo, SP (1989) 609.

[17] Norma EP-1EP-00011-A, "Viscosificante para fluidos usados na exploração e produção de poços de petróleo e gás" Petrobras (2011).

[18] G. Zyła, M. Cholewa, A. Witek, Nanoscale Res. Lett. 7 (2012) 1-10.

[19] K. R. O. Pereira, M. G. F. Rodrigues, F. R. Valenzuela Diaz, Rev. Elet. Mater. Proc. 2.2 (2007) 01-08.

(Rec. 04/04/2014, Rev. 01/08/2014, 07/11/2014, 27/02/2015, Ac. 27/02/2015) 